\title{
Periodic Micro Hole Texturing with Metal Assisted Chemical Etching for Solar Cell Applications: Dependence of Etch Rate on Orientation
}

\author{
Altinoluk $\mathrm{SH}^{1,2^{*}}$, Ciftpinar $\mathrm{HE}^{2,3}$, Demircioglu $\mathrm{O}^{2,4}$, and Turan $\mathrm{R}^{2,3}$ \\ ${ }^{1}$ Electrical and Electronics Engineering Department, Mugla Sitki Kocman University, Mugla, Turkey \\ ${ }^{2}$ Center for Solar Energy Research and Applications (METU-GUNAM), Middle East Technical University, Ankara, \\ Turkey \\ ${ }^{3}$ Department of Physics, Middle East Technical University, Ankara, Turkey \\ ${ }^{4}$ Department of Micro and Nanotechnology, Middle East Technical University, Ankara, Turkey
}

*Corresponding author: Altinoluk SH, Electrical and Electronics Engineering Department, Mugla Sitki Kocman University, Mugla, Center for Solar Energy Research and Applications (METU-GUNAM), Middle East Technical University, Ankara, Turkey, Fax: +90 252223 9280, Tel: +90 252211 5579, E-mail: serra. altinoluk@gmail.com

Citation: Altinoluk SH, Ciftpinar HE, Demircioglu O, Turan R (2017) Periodic Micro Hole Texturing with Metal Assisted Chemical Etching for Solar Cell Applications: Dependence of Etch Rate on Orientation. J Mater Sci Nanotechnol 5(1): 102. doi: 10.15744/2348-9812.5.102

Received Date: March 06, 2017 Accepted Date: May 09, 2017 Published Date: May 11, 2017

\begin{abstract}
Surface texturing is an indispensable process for solar cell fabrication. The interaction of the surface with the incoming sunlight is controlled by texturing in such a way that the absorption is maximized through multiple interactions. Wet and dry etching techniques have been used to create textured surfaces on solar cells. Other than standard alkaline texturing used by the industry, metal assisted etching (MAE) appears to be a promising texturing technique with greater potential application for multi-crystalline solar cell fabrication. It is possible to achieve both random and periodic patterns with MAE which is relatively cheaper than dry plasma etching techniques. In this study, periodic hole patterns with micron sized diameters and periodicity were aimed to be achieved. Etching rate was shown to be strongly dependent on the surface orientation. Uniformly distributed patterns with various diameter and period values were successfully obtained. Fabrication of solar cells on these surface patters were demonstrated. Performance of solar cells was evaluated through parameters like efficiency, open circuit voltage and short circuit current.
\end{abstract}

Keywords: Surface texturing; Light trapping; Metal assisted etching; Periodic patterning; Micro and nano hole texturing of crystalline silicon surface

\begin{abstract}
About The Author
Serra Altinoluk was born in 1983 in Mersin, South Turkey. She got her bachelor and master degrees both in Electrical and Electronics Engineering Department at Mersin University, at 2005 and 2007 respectively. In 2008 she joined to Middle East Technical University, started working as project assistant at Electrical and Electronics Engineering Department. In 2012 she started working as a research assistant in Center for Solar Energy Research and Application, doing her PhD with her supervisor Prof. Rasit Turan. From April 2014 to September 2014 she visited Arizona State University, and later IMEC as a visiting researcher to carry out some of her PhD work.
\end{abstract}

\section{Public Interest Statement}

In order to create a sustainable future for our planet while supplying continuously increasing energy demand of our society, we should use clean energy resources rather than burning fossil fuels like coal, natural gas, and liquid oils. Among the renewable and clean energy sources, solar energy has the greatest potential for providing all energy needs of the human being today and in the future. However, it is required to develop technologies to convert solar energy to other forms like electrical and mechanical energies with high efficiency and low cost. Thus, increasing solar cells efficiency and lowering the material and process costs are the main aim in most of the research efforts. Surface texturing is an indispensable method for light harvesting to develop high efficient solar cells. Metal assisted etching method offers a new and industrially compatible alternative for creating a variety of surface structures that may lead to better performances when compared with conventional pyramid textured counterparts. This work presents some new results on surface texturing by metal assisted etching. 


\section{Introduction}

In general, texturing of the Si wafer surface is performed by creating random pyramids through anisotropic etching process [1]. Although random pyramid texturing is the most common approach for surface texturing today, many research groups focus on alternative structures on the surface to reduce material consumption during the texturing process together with improved light trapping performance. The problem with random pyramid texturing is, the height of the pyramids. The thickness of the substrate is comparable with the height of the pyramids, which makes it impossible to carry out further processes with the substrate. Researchers seek for alternative texturing techniques to overcome material consumption and having to work with thick substrates. Structuring the Si surface by periodic and random cones, rods, wires and holes have already been studied by several research groups [2-5]. For solar cell application, the texture is expected to improve the solar cell performance and decrease the cost of fabrication process. Aforementioned textures have both cons and pros. Rods are freestanding parts of substrate and for tall rods, there is a high possibility of their getting broken. The diameter of the wires is around nanometer level, which makes it very complicated during passivation studies. Wire texturing will end up with optically great, but electrically poor output devices. Among the surface geometries studied, periodic hole patterns were reported to be the most promising structure for an effective light trapping [6]. Unlike rods, holes can freely stand and make it possible to work with thin substrates. The scope of this study is to investigate the use of metal assisted etching (MAE) to create periodic hole patterns on Si wafer for solar cell applications. It is aimed to increase optical performance of the solar cell while keeping electrical losses as small as possible. In this paper, we report on patterning of crystalline silicon (c-Si) surface by MAE which is a wet chemical etching method for the fabrication of random and periodic structures with the help of catalytic effect of metals. Metal layers can be used as both direct catalyst and mechanical support [7].

In order to obtain periodic patterning, there should be a lithography step. With optical lithography, we can define the pattern of the textures on the surface and during etching step predefined parts of the surface will be etched. For random texturing, there is no need for the definition of patterns. MAE was used as an electroless etching technique utilizing a discontinuous layer of metal in suitable oxidant such as hydrogen peroxide $\left(\mathrm{H}_{2} \mathrm{O}_{2}\right)$ and hydrofluoric acid (HF) to obtain porous Si and porous III-V compound semiconductor by Li et. al. in 2000 and 2002 in contrast to the conventional anodic etching method for porous semiconductor formation [8]. During MAE, noble metals are used to initiate local oxidation and reduction reactions [9]. Metals such as gold $(\mathrm{Au})$, platinum $(\mathrm{Pt})$ and silver $(\mathrm{Ag})$, deposited on the surface of a semiconductor (e.g. Si) serve as a local cathode to catalyze the reduction of oxidants (e.g. $\mathrm{H}_{2} \mathrm{O}_{2}$ ) producing holes. Random and periodic patterns can be obtained with the help of noble metals and appropriate chemical components [10].

\section{Experimental Details}

Schematic representation of periodic hole array formation with metal assisted etching process is shown in Figure 1. The hole pattern was first defined by the photoresist through a lithography process regardless of orientation. A thin layer of Ag was then evaporated on patterned surface which is followed by a lift off process which left behind circular metal dots on the surface shown in Figure 1-b. During MAE, Si under metal dots was etched away through chemical reactions described elsewhere, array of holes was then formed. In the final step of MAE process, the residual metal was removed using aqua regia solution [11].

a)

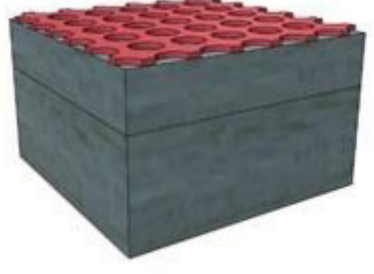

b)

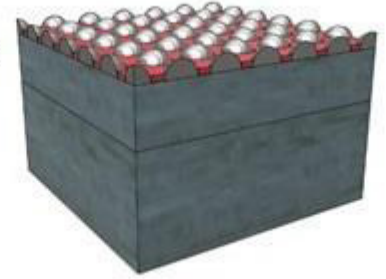

c)

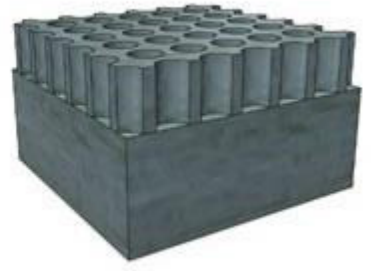

Figure 1: MAE process sequence with periodic patterning a) Surface patterning, b) Metal evaporation, c) Wet chemical etching and removal of resist and metal residuals

In this study, p-type Si wafers with both (111) and (100) orientations and resistivity of 1-5 $\Omega$-cm were used. Fabrication steps of a standard solar cell with aluminum back surfaces field (Al-BSF) is shown in Figure 2. The standard solar cell fabrication process starts with RCA cleaning $\left(5 \mathrm{H}_{2} \mathrm{O}+\mathrm{NH}_{4} \mathrm{OH}+\mathrm{H}_{2} \mathrm{O}_{2}\right)$ [12]. After the cleaning step, depending on the dimensions of the textures aimed to be created on top of the surface, appropriate resist is selected. Depending on the diameter and the pitch sizes of the holes, unique lithography recipes have been developed. During MAE silicon deposited with metals is immersed into $\mathrm{HF}_{2} \mathrm{H}_{2} \mathrm{O}_{2} /$ $\mathrm{H}_{2} \mathrm{O}$ solution, where metal coatings facilitate the etching [13]. Thanks to the novel electrochemical properties of the interaction between $\mathrm{Si}$ and active noble metals, there is an electrokinetic model which satisfactorily explains the microscopic dynamic origin of motility of metal particles in Si. According to this model, the power generated in the bipolar electrochemical reaction at a metal particle's surface can be directly converted into mechanical work to propel the tunneling motion of metal particles in Si [14,15]. The chemical and electrochemical reactions occurring preferentially near the noble metal can be briefly defined as: 
- At the cathode (the metal): $\mathrm{H}_{2} \mathrm{O}_{2}$ is reduced as $\mathrm{H}_{2} \mathrm{O}_{2}+2 \mathrm{H}^{+} \rightarrow 2 \mathrm{H}_{2} \mathrm{O}+2 \mathrm{~h}^{+}$

- At the anode (the silicon substrate): The Si substrate is oxidized and dissolved. Although the reaction is controversial, there are three main models proposed for the dissolution process of Si as given below :

$$
\begin{aligned}
& \mathrm{Si}+4 \mathrm{~h}++4 \mathrm{HF} \rightarrow \mathrm{SiF}_{4}+4 \mathrm{H}+\& \mathrm{SiF}_{4}+2 \mathrm{HF} \rightarrow \mathrm{H}_{2} \mathrm{SiF}_{6} \\
& \mathrm{Si}+4 \mathrm{HF}_{2} \rightarrow \mathrm{SiF}^{2-}{ }_{6}+2 \mathrm{HF}+\mathrm{H}_{2} \uparrow+2 \mathrm{e}^{-} \\
& \mathrm{Si}+2 \mathrm{H}_{2} \mathrm{O} \rightarrow \mathrm{SiO}_{2}+4 \mathrm{H}^{+}+4 \mathrm{e}^{-} \& \mathrm{SiO}_{2}+6 \mathrm{HF} \rightarrow \mathrm{H}_{2} \mathrm{SiF}_{6}+2 \mathrm{H}_{2} \mathrm{O}
\end{aligned}
$$

The most critical feature of this reaction scheme is the generation of $h+$ from $\mathrm{H}_{2} \mathrm{O}_{2}$ and the reduction of $\mathrm{H}^{+}$to form $\mathrm{H}_{2}$, both of which are facilitated by the metal particles $[13,16]$. After wet chemical etching, remaining metals have been removed with aqua regia (nitric acid + hydrochloric acid $=1: 3$ ). Following metal removal step, wafers were doped with $\mathrm{P}_{\text {using }} \mathrm{POCl}_{3}$ at temperatures lower than $850^{\circ} \mathrm{C}$. After $\mathrm{P}$ diffusion, silicon nitride ( $\mathrm{SiNx}$, Si-rich where $0<\mathrm{x}<1.33$ ) was deposited by plasma enhanced chemical vapor deposition (PECVD) to passivate the surface and reduce the reflection from the surface. During the formation of contacts, $\mathrm{Ag}$ evaporation was applied for front contacts. The mask was designed in such a way that Ag fingers were aligned to stay on unetched regions during MAE. Rear side of the wafer was fully covered with Aluminum. As a last step of the fabrication sequence, laser edge isolation was carried out to isolate front side of the cell from the rear side.

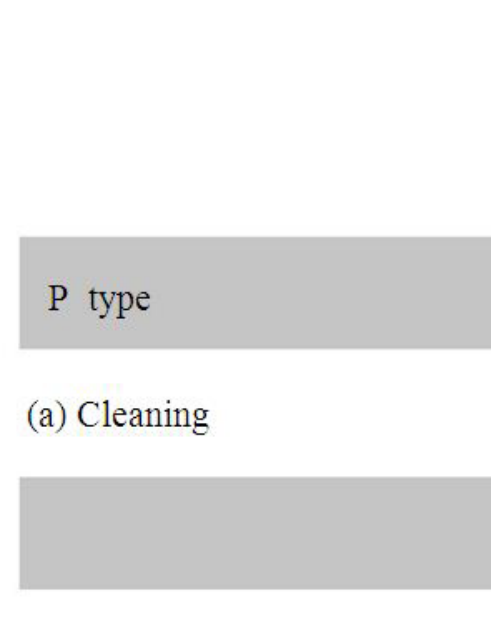

(b) Photoresist coating

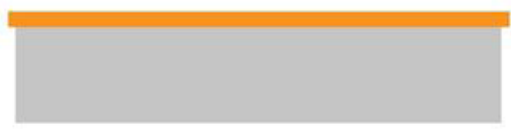

(c) Photolithograhy

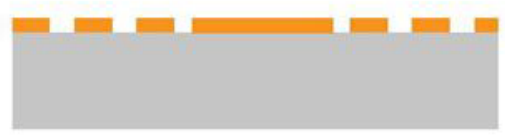

(d) MAE
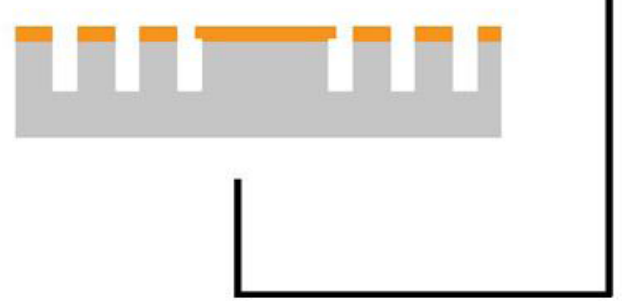

Figure 2: Process flow of solar cell fabrication with periodic hole textured front surface: a) cleaning of the wafers, b) photoresist coating with appropriate recipe depending on the dimenison of the textures, c) photolithography, d) MAE process, duration is defined according to the desired texture depth, e) photoresist and metal removal, f) doping, g) antireflection $(\mathrm{SiNx})$ coating for passivation, h) metallization with Ag for front and Al for back contacts, i) edge isolation

A wide range of hole diameter and distribution was studied from micron to submicron levels [17]. Resist coating recipe was optimized according to required hole diameter and the pitch (periodicity) values. The schematic representation of a hole textured surface including dimensions is shown in Figure 3. 


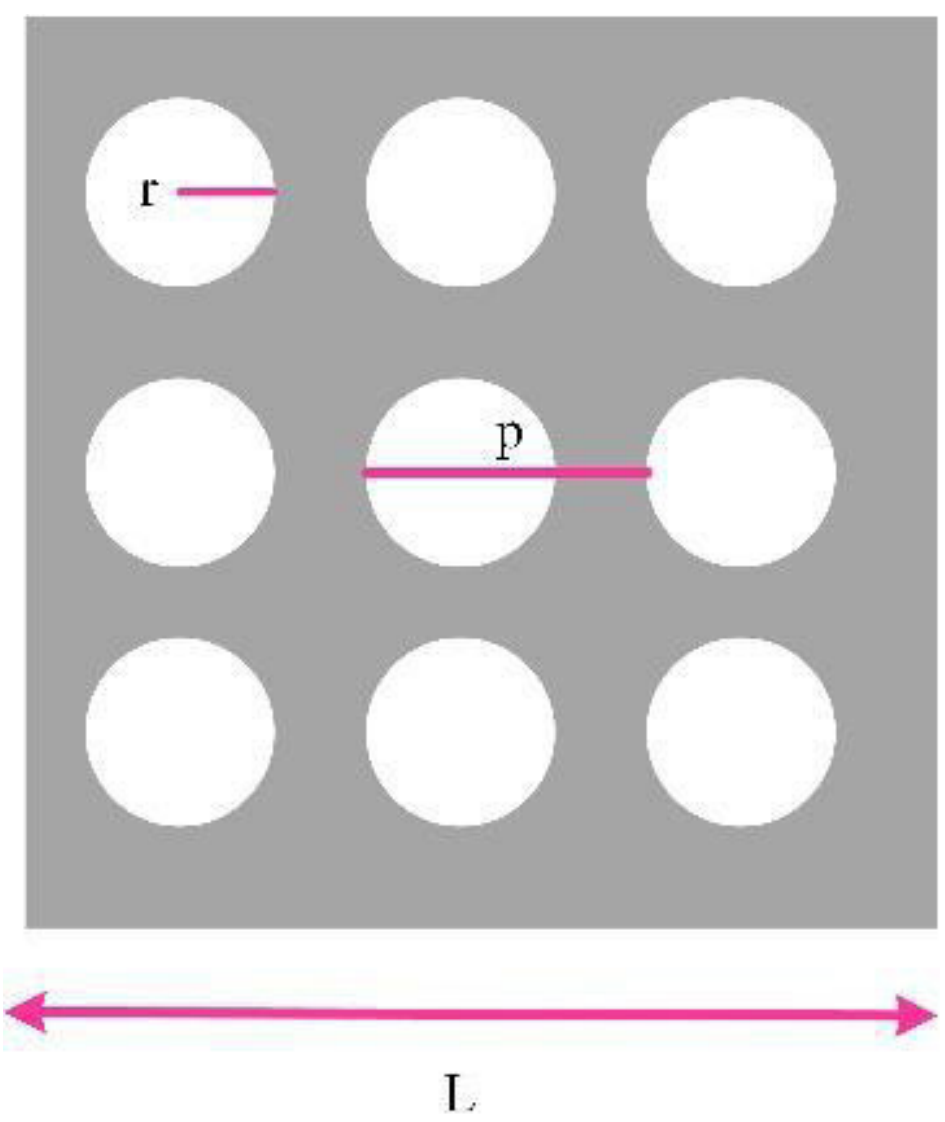

Figure 3: Schematic representation of radius (r), pitch (p) and length of the sample (L)

\section{Dependence of Etch Rate on Orientation During MAE}

In principle, chemical etching techniques are dependent on the surface orientation due to the fact that the bonding energy of the surface atoms can be very different for different crystallographic direction. The (111) surface has two surfaces with atoms having one free bond ending up with a low surface energy, one with very high activation energy due to three back bonds. On the contrary,

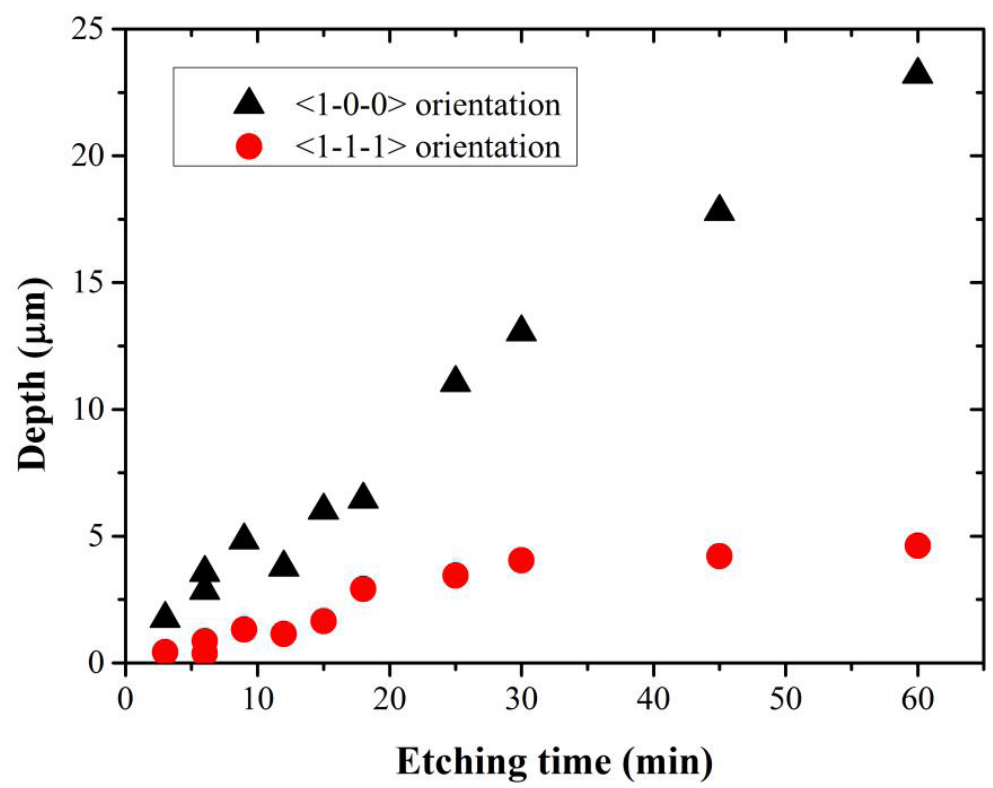

Figure 4: Etch rate comparison of wafers having $3 \mu \mathrm{m}$ hole diameter and $6 \mu \mathrm{m}$ pitch size coated with $25 \mathrm{~nm}$ Ag having (100) and (111) orientations. 
(111) surface has lower activation energy [10]. For this reason, (111) oriented wafers have usually lower etch rate values compared to (100) orientation [18]. In order to see the degree of orientation dependence of MAE patterning, we performed a series of simultaneous experiments for (100) and oriented wafers. Figure 4 shows the depth of the holes created by MAE as a function of etching time for the sample having $3 \mu \mathrm{m}$ hole diameter and $6 \mu \mathrm{m}$ pitch size.

The etch rates for this particular case were found to be $0.13 \mu \mathrm{m} / \mathrm{min}$ and $0.43 \mu \mathrm{m} / \mathrm{min}$ for (111) and (100) orientations, respectively. Large difference between etch rates of these two orientation is consistent with the expectation. Figure 5 shows representative SEM images of the holes having same diameter and variable pitch sizes. These patterns were prepared on the same wafer and subjected to same process conditions. We see that hole patterns with perfect circular shapes and different distribution are formed with MAE. In some cases additional patterns, randomly distributed wire inside holes, were observed in the hole as shown in Figure 5. The control of the diameter and the pitch size is quite well so that the intended geometries can be achieved without any deformation. It is however clear that formation of deep holes are hardly possible with (111) surface orientation due to the low etch rates.

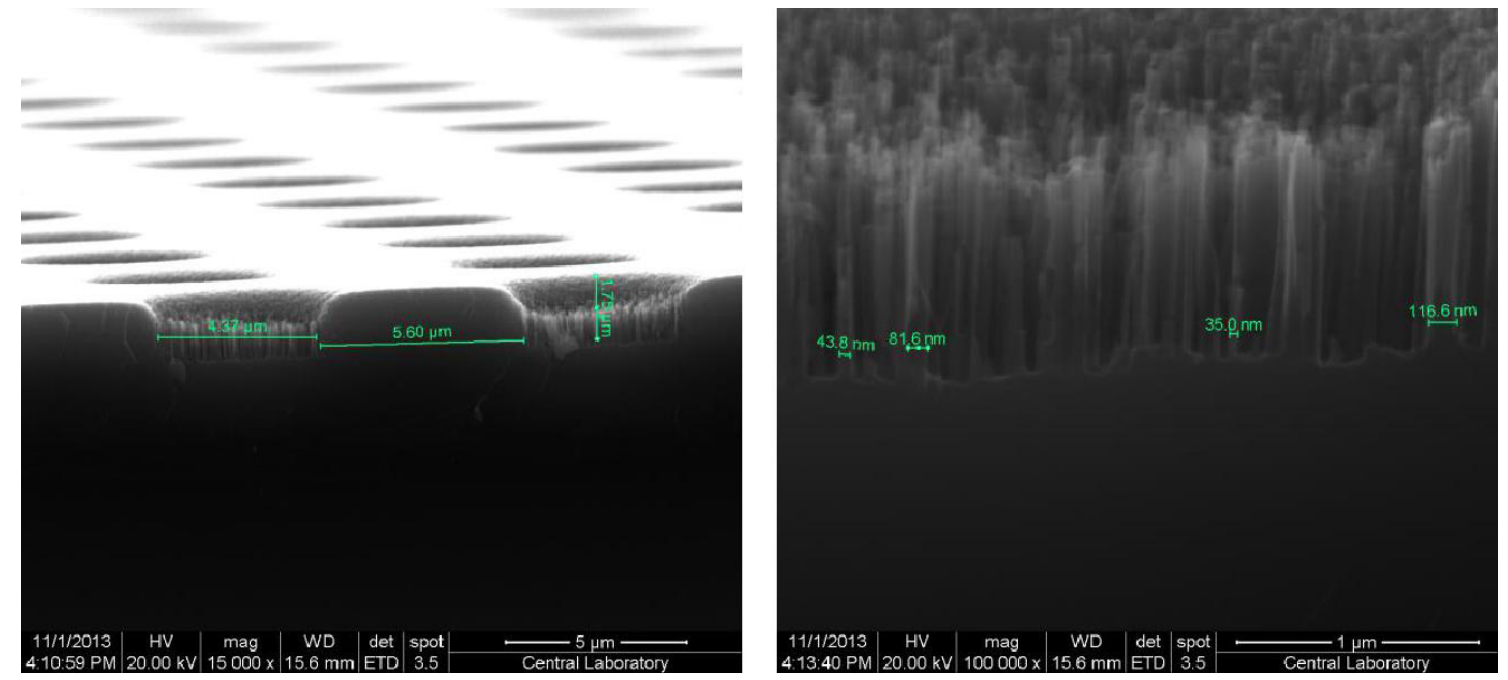

Figure 5: SEM image of (100) oriented wafer with $5 \mu \mathrm{m}$ diameter and $9 \mu \mathrm{m}$ pitch size

Figure 6 represents the SEM images of surfaces obtained after MAE process. The wafers shown here were having (111) orientation. The diameter of the predefined holes was $3 \mu \mathrm{m}$, thanks to successful lithography recipe to end up with desired distribution of holes, diameter and pitch sizes. Optical properties of the patterned surface were studied through reflection measurements as shown in Figure 7. Samples used in this study have the hole diameter of $5 \mu \mathrm{m}$ and the pitch sizes of $6,8,10 \mu \mathrm{m}$. It can be seen that the lowest reflection value was obtained from the sample having the smallest pitch size. The reflection from this sample is even lower than the pyramid textured samples. The texture with the lowest pitch size refers to the sample with the most dense surface having the highest hole volume on top of the surface. For optical performances the surfaces textured with MAE were analyzed without SiNx coating, on the other hand electrical performances of the solar cells were obtained after standard solar cell fabrication steps including antireflection coating.
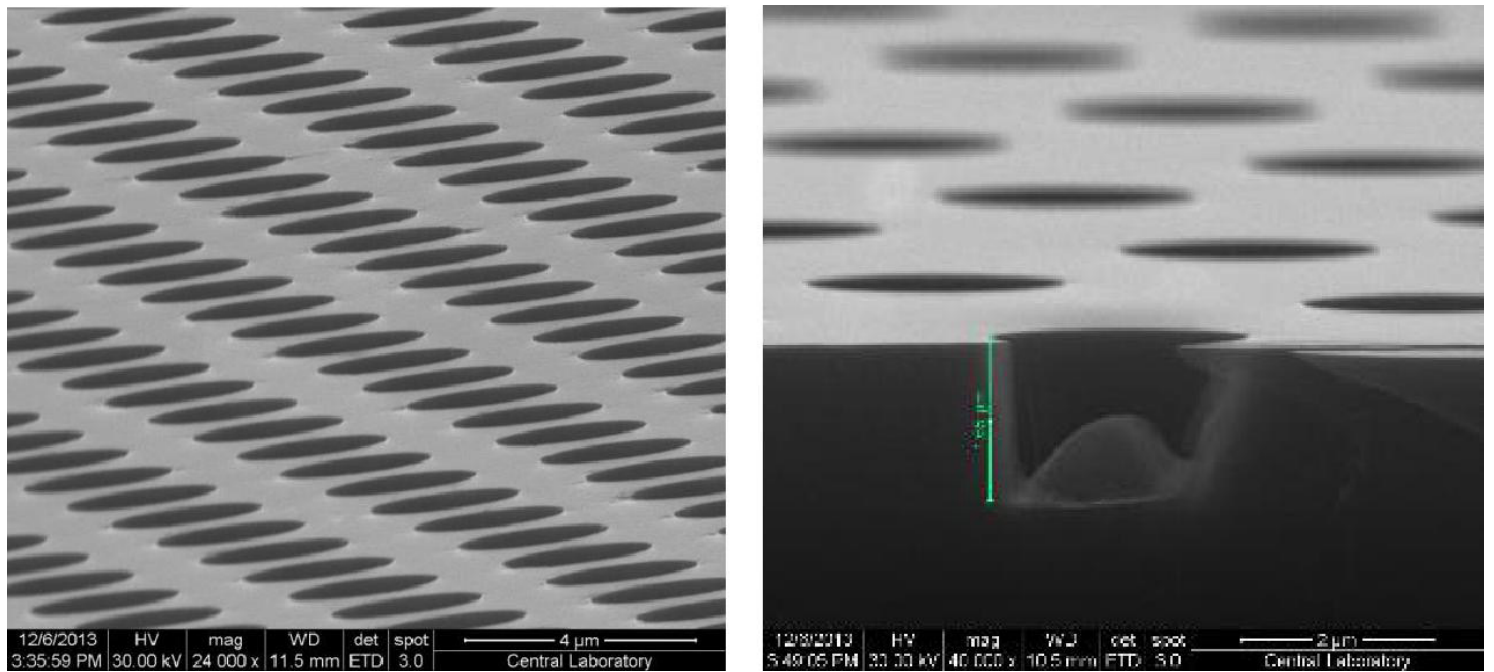

Figure 6: SEM images of (111) oriented wafer with $3 \mu \mathrm{m}$ diameter and $5 \mu \mathrm{m}$ pitch size 


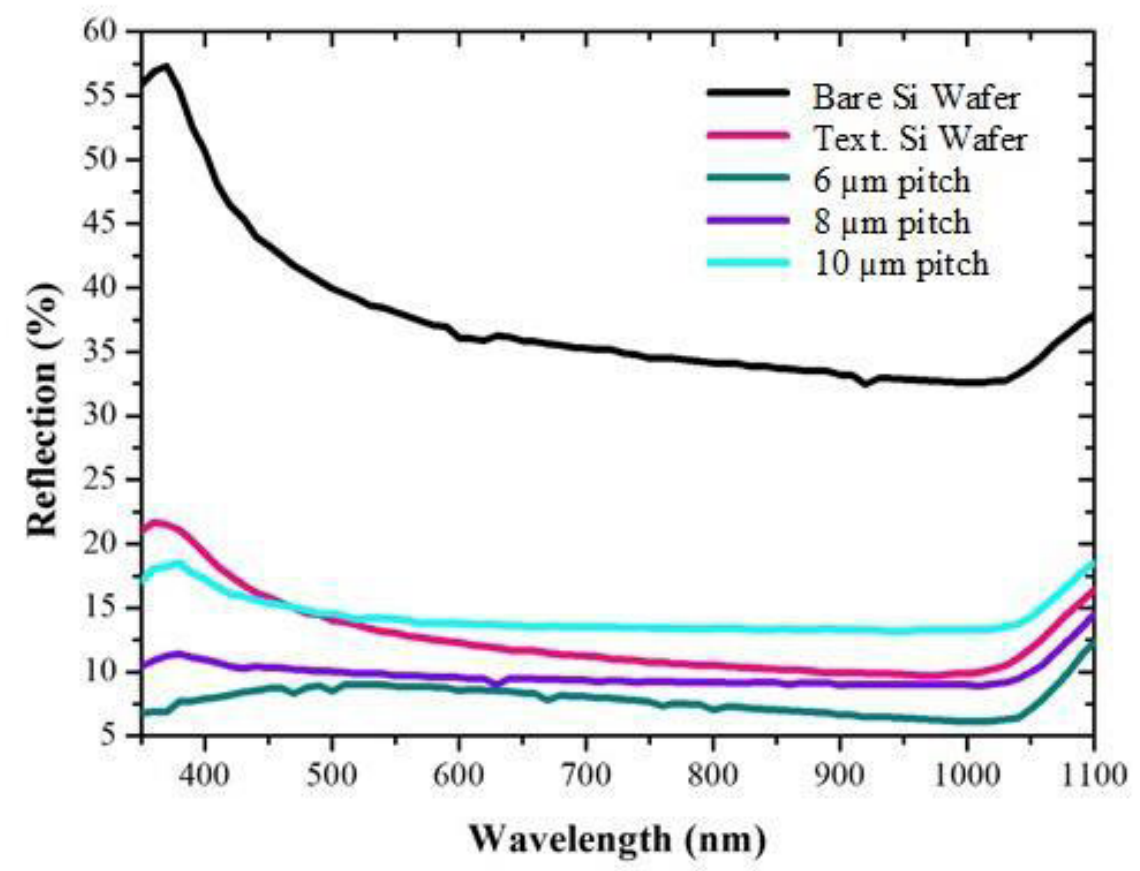

Figure 7: Reflection spectra comparison depending on holes with $5 \mu \mathrm{m}$ diameter and 6, 8, $10 \mu \mathrm{m}$ pitch sizes. Sample with pyramid textures made by alkaline etching is also shown (pink curve). No antireflection coating was applied to these samples

\section{Solar Cells Textured with MAE}

I-V curves of the solar cells fabricated on the sample with $5 \mu \mathrm{m}$ diameter are shown in Figure 8. Solar cell parameters extracted from these curves are tabulated in Table 1. It can be seen that solar cells with reasonably well I-V curves have been obtained on hole textured surface. The effect of hole distribution is mostly pronounced in the short circuit current (Jsc) value which increases with increasing pitch size significantly. Highest values were obtained with largest pitch size and the deepest structure which correspond to lowest hole density on the surface. This result indicates that the charge collection efficiency worsens with increasing hole volume on the surface. On the other hand, the open circuit voltage (Voc) value was found to be less sensitive to the pitch size. It is however lower than one might expect from a c-Si solar cell device. This is due to the poor surface quality after MAE process.

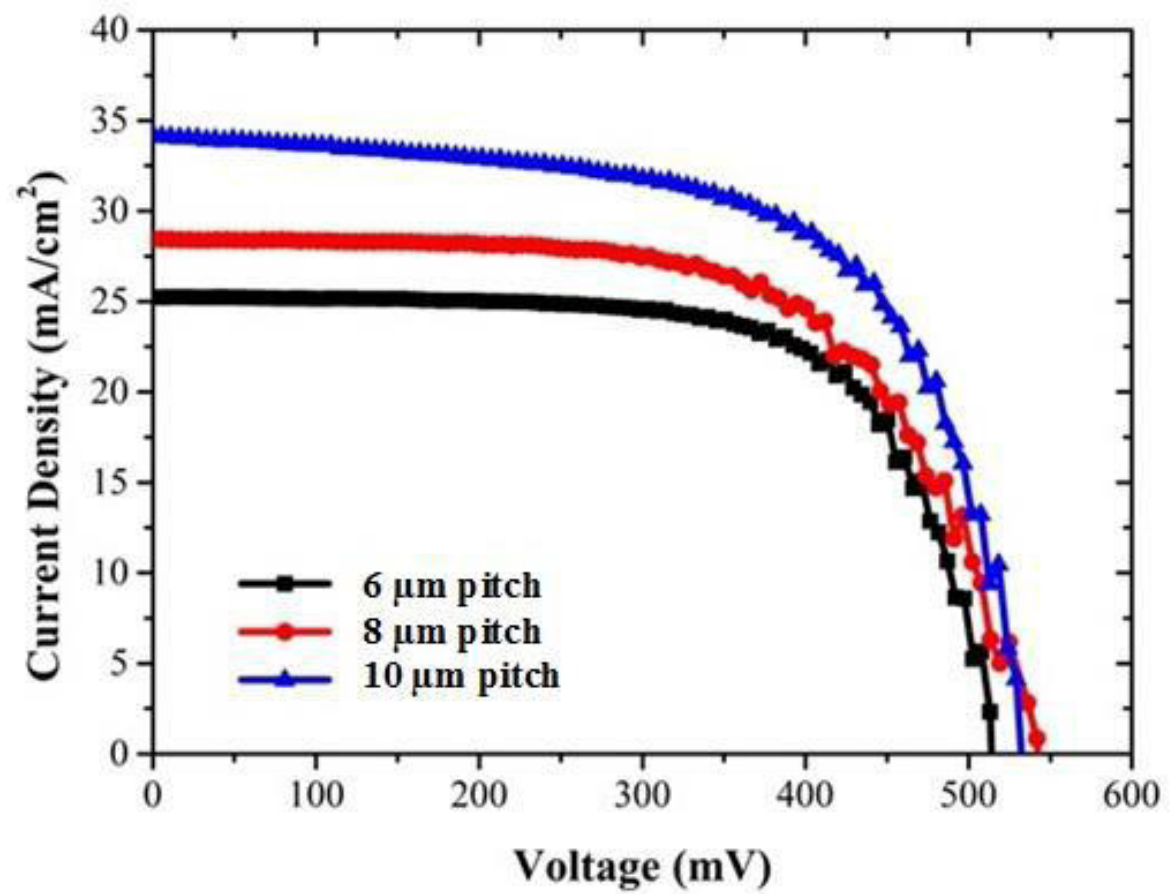

Figure 8: Current density versus voltage graphs of samples with $5 \mu \mathrm{m}$ diameter and $6,8,10 \mu \mathrm{m}$ pitch sizes subjected to one hour wet chemical etching 
In this work we have not attempted to optimize surface passivation. An effective surface passivation would improve the open circuit voltage significantly. In addition to better passivation optimizations, with the fabrication of deeper structures, with aforementioned pitch sizes, it is clear that we can end up with better cell performances [18,19]. $2 \mu \mathrm{m}$ in diameter and $23.2 \mu \mathrm{m}$ in length with a better passivation process step ended up with $13 \%$ of cell performance [9]. Unlike our resist coating technique, surface patterning was conducted with circular shaped photoresist dot arrays and optimized antireflective coating process step [9].

The solar cell performances shown in Table 1 were subjected to process steps shown in Figure 2.

\begin{tabular}{|c|c|c|c|c|c|}
\hline Diameter: $\mathbf{5} \boldsymbol{\mu m}$ & $\begin{array}{c}\text { Depth } \\
(\boldsymbol{\mu m})\end{array}$ & $\begin{array}{c}\text { Voc } \\
(\mathbf{m V})\end{array}$ & $\begin{array}{c}\text { Jsc } \\
\left(\mathbf{m A} / \mathbf{c m}^{2}\right)\end{array}$ & $\begin{array}{c}\text { FF } \\
(\mathbf{\%})\end{array}$ & $\begin{array}{c}\boldsymbol{\eta} \\
(\%)\end{array}$ \\
\hline $6 \mu \mathrm{m}$ pitch size & 17.48 & 512.1 & 25.2 & 69 & 8.9 \\
\hline $8 \mu \mathrm{m}$ pitch size & 19.32 & 531.6 & 28.4 & 64.1 & 9.6 \\
\hline $10 \mu \mathrm{m}$ pitch size & 23.04 & 531.8 & 34.1 & 63.7 & 11.5 \\
\hline Plane & -- & 564.9 & 20.9 & 75.8 & 9 \\
\hline
\end{tabular}

Table 1: Performance parameters of solar cells textured with $5 \mu \mathrm{m}$ diameter holes and 6, 8, $10 \mu \mathrm{m}$ pitch sizes

\section{Discussions}

Nano wires inside the holes can be eliminated with an additional chemical process in order to obtain smoother hole textures especially for (100) oriented wafers. Although these unintended textures ended up with lower reflection values, they were difficult to be passivated. This problem can be solved with improved passivation process step. Atomic layer deposition process can an alternative passivation technique for textured surfaces.

\section{Conclusion and Future Work}

We have successfully employed metal assisted etching technique to create periodic hole patterns on Si wafer as light trapping medium in solar cell applications. As expected, etch rate along (111) direction was found to be significantly slower compared to that along (100) direction. Thus (100) orientation provides us with a wider range of surface dimensions for MAE texturing studies. Performance of solar cells with hole patterns has been evaluated through different hole pitch sizes. We have observed that the cell performance improves with increasing pitch size as a result of less hole density. The open circuit voltage is generally low due to the poor surface quality and found to be less sensitive to the hole distribution. By eliminating the wires inside the holes and with better optimization of antireflection coatings and metallization schemes, the solar cell performances are expected to improve more.

\section{References}

1. O. El Daif, Trompoukis C, Niesen B, Yaala MB, Sharma PP et al. (2013) Inverted random nanopyramids patterning for crystalline silicon photovoltaics. Inst Phys $\mathrm{J}$

2. Z Xiong, F Zhao, J Yang, X. Hu (2010) Comparison of optical absorption in Si nanowire and nanoporous Si structures for photovoltaic applications. Appl Phys Lett 96: 2010-3.

3. C. Trompoukis, A Herman, OE Daif, V Depauw, DV Gestel et al. (2012) Enhanced absorption in thin crystalline silicon films for solar cells by nanoimprint lithography. Proc SPIE 8438: 84380R.

4. QG Du, CH Kam, HV Demir, HY Yu, XW Sun (2011) Enhanced optical absorption in nanopatterned silicon thin films with a nano-cone-hole structure for photovoltaic applications. Opt. Lett 36: 1713.

5. SY Chou, PR Krauss, PJ Renstrom (1996) Nanoimprint lithography. J Vac Sci Technol B Microelectron Nanom Struct 14: 4129.

6. SE Han, G Chen (2010) Optical absorption enhancement in silicon nanohole arrays for solar photovoltaics. Nano Lett 10: 1012-5.

7. RW Wu, GD Yuan, KC Wang, TB Weil, ZQ Liu et al. (2016) Bilayer - metal assisted chemical etching of silicon microwire arrays for photovoltaic applications. AIP Adv 6: 25324.

8. X Li (2012) Metal assisted chemical etching for high aspect ratio nanostructures: A review of characteristics and applications in photovoltaics. Curr Opin Solid State Mater Sci 16: 71-81.

9. HD Um, N Kim, K Lee, I Hwang, JH Seo et al. (2015) Versatile control of metal-assisted chemical etching for vertical silicon microwire arrays and their photovoltaic applications. Sci Rep 5: 11277.

10. TM Adams, R A Layton (2010) Introductory MEMS: Fabrication and applications. Springer.

11. F Es, M Kulakci, R Turan (2016) An Alternative Metal-Assisted Etching Route for Texturing Silicon Wafers for Solar Cell Applications. IEEE J. Photovoltaics 6: $440-6$.

12. W Kern (2007) RCA Critical Cleaning Process. Micro Tech Sys Inc 1-7.

13. X Li, PW Bohn (2016) Metal-assisted chemical etching in Metal-assisted chemical etching in HF/ H2O2 produces porous silicon. 2572: 1998-2001.

14. BK Peng, A Lu, R Zhang, S Lee (2008) Motility of Metal Nanoparticles in Silicon and Induced Anisotropic Silicon Etching. Adv Funct Mate 18: 3026-35.

15. K Peng, H Fang, J Hu, Y Wu, J Zhu (2006) Metal-Particle-Induced, Highly Localized Site-Specific Etching of Si and Formation of Single-Crystalline Si Nanowires in Aqueous Fluoride Solution. Euro J Chem 12: 7942-7947.

16. Y Harada, X Li, PW Bohn, RG Nuzzo (2001) Catalytic Amplification of the Soft Lithographic Patterning of Si. Nonelectrochemical Orthogonal Fabrication of Photoluminescent Porous Si Pixel Arrays. J Am Chem Soc 123: 8709-17.

17. SH Altinoluk, Ciftpinar HE, Demircioglu O, Firat Es, Baytemir G et al. (2016) Light Trapping by Micro and Nano-hole Texturing of Single-crystalline Silicon Solar Cells. Energy Procedia 92: 291-6. 
18. G Lu, Huang M, Cuma M, Liu F (2005) Relative stability of Si surfaces : A first-principles study. Surface Sci 588: 61-70.

19. A El Amrani, A Bekhtari, A El Kechai, H. Menari, L Mahiou (2015) Efficient passivation of solar cells by silicon nitride. Vaccum 120: 95-9.

20. X Li (2012) Metal assisted chemical etching for high aspect ratio nanostructures : A review of characteristics and applications in photovoltaics. Curr Opin Solid State Mater Sci 16: 71-81.

\footnotetext{
Submit your next manuscript to Annex Publishers and benefit from:

$>$ Easy online submission process

> Rapid peer review process

> Online article availability soon after acceptance for Publication

> Open access: articles available free online

More accessibility of the articles to the readers/researchers within the field

Better discount on subsequent article submission

Submit your manuscript at 